\title{
A ORGANIZAÇÃO DOS ESPAÇOS NA EDUCAÇÃO INFANTIL
}

\author{
Adriana Aparecida da Cruz Alves ${ }^{1}$ \\ Andréa Vicunã Ferreira da Silva Mesquita ${ }^{2}$ \\ Elaine Aparecida Bernardo ${ }^{3}$ \\ Elizângela Leite da Silva Macedo ${ }^{4}$ \\ Gleice Aparecida Martins ${ }^{5}$ \\ Silvia Casmal de Freitas ${ }^{6}$
}

RESUMO: Este artigo analisa a concepção de espaços na educação infantil. O objetivo é analisar a importância do espaço para a aprendizagem e o desenvolvimento infantil, verificar como ele facilita a prática educativa e como é utilizado no cotidiano pelas instituições. É abordada a importância da organização espacial no processo educacional e a adaptação dos espaços físicos conducentes à qualidade espacial. A organização da sala é considerada uma importante ferramenta educativa que auxilia na prática educativa e oferece à criança diferentes experiências. Isso reforça a importância da pesquisa e do ensino que busquem dar um olhar diferenciado à organização dos espaços nas instituições de educação infantil.

Palavras-chave: Organização dos espaços. Creches. Aprendizagem. Desenvolvimento; Prática educativa.

ABSTRACT: This article analyzes the design of spaces in early childhood education. The objective is to analyze the importance of the space for learning and child development, verifying how it facilitates educational practice and how it is used in everyday life by institutions. The importance of spatial organization in the educational process and the adaptation of physical spaces conducive to spatial quality is addressed. The organization of the room is considered an important educational tool that helps in educational practice and offers the child different experiences. This reinforces the importance of research and teaching that seek to give a different look to the organization of spaces in early childhood education institutions.

Keywords: Space organization. Day care centers. Learning. Development. Educational practice.

I Graduada em Pedagogia pela Univerisdade de Cuiabá - UNIC, Especialista em Educação Infantil e Alfabetização pela Faculdade Poliensino - FP.

${ }^{2}$ Graduada em Pedagogia pela Faculdade INTERVALE, Especialista em Educação Infantil pela Faculdade Afirmativo.

3 Graduada em Pedagogia pela Universidade Estadual de Mato Grossso - UNEMAT, Especialista em Psicopedagogia pelo Instituto Cuiabano de Educação - ICE.

4 Graduada em Pedagogia Faculdade Varzeagrandense de Ciências Humanas, Especialista em Educação Infantil e Especial pela Faculdade das Águas Emendadas - FAE.

${ }_{5}$ Graduada em Pedagogia pela Univerisdade de Cuiabá - UNIC, Especialista em Psicopedagogia Institucional pela Faculdade São Luíz.

${ }^{6}$ Graduada em Pedagogia pela Univerisdade de Cuiabá - UNIC, Especialista em Educação Infantil com Ênfase em Alfabetização pela Faculdade INVEST de Ciências e Tecnologia. 


\section{INTRODUÇÃO}

O presente artigo apresenta uma discussão acerca da organização dos espaços naEducação Infantil, tendo como objetivo tratar da organização dos espaços nas creches e sua importância para a aprendizagem e o desenvolvimento da criança, como também a maneira como os espaços facilitam a prática educativa e como são utilizados no desenvolvimento das atividades. Apresenta uma breve história e contextualiza a educação infantil, creche, hoje sendo a matricula um direito da criança, tendo como função o cuidar e o educar.

A organização do espaço no processo educativo, auxilia e contribui para o desenvolvimento e aprendizagem da criança, as diferentes organizações que favorecem a interação e experiências significativas, facilitando a prática educativa.

O tema se insere no contexto educacional da atualidade, com o objetivo de analisar os espaços conforme os requisitos presentes nos documentos legais, e escritas de diferentes autores sobre o tema, de modo a favorecer a qualidade do ensino na Educação Infantil.

O trabalho proposto auxilia na percepção da qualidade dos espaços, como também na construção e adequação de ambientes propícios para atividades pedagógicas, auxiliando o educador em sua prática diária e contribuindo de modo significativo para a criança. Neste contexto, justifica-se a relevância e importância deste artigo, com proposito de investigar a organização dos espaços na Educação Infantil.

\section{DESENVOLVIMENTO}

\section{I Educação Infantil}

O atendimento às crianças em creches é uma realidade no Brasil, com a função de educar e cuidar, portanto o significado e o atendimento oferecido mudaram com o passar dos anos. De acordo com a Lei das Diretrizes e Bases da Educação Nacional (Lei 9394/96) no Art. 29: "a Educação Infantil, primeira etapa da educação básica, tem como finalidade o desenvolvimento integral da criança de até 5 anos, em seus aspectos físicos, psicológico, intelectual e social, complementando a ação da família e da comunidade." O atendimento oferecido em creches para crianças de até três anos de idade, e em pré-escolas para crianças de quatro a cinco anos de idade. 
Para Carvalho e Rubiano (1995) a Educação Infantil tem função educativa, onde trabalha com a realidade vivenciada pelas crianças ampliando seus conhecimentos com atividadesconcretas. Os professores devem garantir condições educativas, preocupando-se com a organização dos espaços para o desenvolvimentoe aprendizagem das crianças.

\begin{abstract}
$\mathrm{O}$ atendimento institucional à criança pequena, no Brasil e no mundo, apresenta ao longo de sua história concepções bastante divergentes sobre sua finalidade social. Grande parte dessas instituições nasceram com o objetivo de atender exclusivamente às crianças de baixa renda $[. .$.$] o atendimento era entendido como$ um favor oferecido para poucos, selecionados por critérios excludentes. A concepção educuacional era marcada por características assistencialistas, sem considerar as questões de cidadania ligadas aos ideais deliberdade e igualdade (REFERENCIAL CURRICULAR NACIONAL PARA A EDUCAÇÃO INFANTIL, I998, p.I7).
\end{abstract}

Para as Diretrizes Curriculares Nacionais da Educação Básica (2013) a história das creches e pré-escolas começa a partir do século XIX, marcada por diferenciações referente à classe social das crianças, onde a concepção da educação nas creches para crianças pobres compreendia o cuidar, atividades ligadas ao corpo, órgão assistencial, sendo que para crianças os grupos privilegiados o educar e a promoção intelectual, com práticas educativas. Estes momentos caracterizaram-se pela ausência de investimentos públicos e sem profissionais qualificados.

A Constituição de 1988, coloca como direito social das crianças o atendimento em creches e pré-escolas. Este direito assegurado na ConstituiçãoFederal, e contemplado também na Lei de Diretrizes e Bases da Educação. A EducaçãoInfantil é parte integrante da Educação Básica Brasileira, LDB (9394/96) “Art. 2I. A educaçãoescolar compõe-se de: I educação básica, formada pela educação infantil, ensino fundamentale ensino médio; II educação superior”. O atendimento em creches é direito da criança, mas opção da família por não ser obrigatória e dever do estado, colabora significativamente para a criança, pois a mesma objetiva o cuidar e educar, as vivências são fundamentais para o desenvolvimento da criança em todas os níveis.

\title{
2.2 A organização do espaço no processo educativo
}

A importância do espaço e da sua organização para a educação, desenvolvimento e aprendizagem das crianças muitas vezes não é reconhecida, apenas é analisada como um pano de fundo e não é evidenciada a importância no processo educativo, uma vez que o espaço é viabilizado para além da prática pedagógica e limita este processo. 
O espaço na instituição de educação infantil deve propiciar condições para que as crianças possam usufruí-lo em benefício do seu desenvolvimento e aprendizagem. Pratanto, é preciso que o espaço seja versátil e permeável à sua ação, sujeito às modificações propostas pelas crianças e pelos professores em função das ações desenvolvidas (Referencial Curricular Nacional para a Educação Infantil (1998, p. 69).

A importância da organização do espaço na Educação Infantil, na fase de o a 3 anos período em que a criança frequenta a creche, é um fator predominante para o desenvolvimento e aprendizagem da criança.

O processo de desenvolvimento humano deve ser entendido como uma construção formada pelas relações que o indivíduo faz com o outro e com o mundo físico [...] praticamente depende das qualidades inatas do indivíduo somadas às interações realizadas durante seu crescimento, com experiências em sua trajetória oportunizadas pelas pessoas nela envolvidas. Aprendizagem acontece por meio de uma interação social somada às oportunidades de experiências significativas que o individuo vivencia (NISTA-PICCOLO \& MOREIRA, 20I2, p. 4I-46).

Ao tratar da organização dos espaços em diferentes ambientes, para promover o desenvolvimento e aprendizagem das crianças. David \& Weinstein (1987) apud Carvalho \& Rubiano (1995, p. I09) consideram que "todos os ambientes construídos paracrianças deveriam atender cinco funções relativas ao desenvolvimento infantil [...]”.

A primeira função relativa ao desenvolvimento infantil remete a promover identidade pessoal, pois a criança apesar de conviver em ambientes coletivos, precisa saber que ela é única,portanto necessita ter a sua identidade em sala de aula, personalizando e decorando seus objetospessoais.

Como segunda função as autoras destacam, promover o desenvolvimento de competência, "o ambiente infantil deve ser planejado para dar oportunidade às crianças desenvolverem domínio e controle sobre seu habitat, fornecendo instalações físicas convenientes para que as crianças satisfaçam suas necessidades" (DAVID \& WEINSTEIN 1987 apud CARVALHO \& RUBIANO, 1995, p. II2). O espaço é organizado de maneira quea criança realize e faça suas coisas, sentindo-se competente, sem a intervenção constante de umadulto, construindo confiança em si mesma.

Promover oportunidades para crescimento está destacada como a terceira função, no qual o espaço precisa oferecer a criança oportunidade de realização de movimentos corporais para conhecer e controlar o próprio corpo, além de promover, favorecer e estimular o uso dos cinco sentidos. 
Acerca da quarta função relativa ao desenvolvimento infantil as autoras apresentam, promover sensações de segurança e confiança, onde o ambiente precisa ser organizado de forma criativa e segura, permitindo sua exploração através de diferentes movimentos corporais, onde o espaço transmita segurança e conforto a criança.

Como quinta e última função está promover oportunidades para contato social e privacidade: "Um ambiente deve ser planejado, tanto em termos de espaço como de objetos disponíveis, para atender ambas as necessidades, de contato social e privacidade" (DAVID \& WEINSTEIN, 1987 apud CARVALHO \& RUBIANO, 1995, p. II2).

O professor deve organizar de forma adequado os espaços disponíveis em sua prática, pois além de auxiliar na construção da aprendizagem é um elemento essencial para um processo educativo de qualidade. Conforme o Referencial Curricular Nacional para a Educação Infantil (I998, p. 68) “A estruturação do espaço, a forma como os materiais estão organizados, a qualidade e adequação dos mesmos são elementos essenciais de um projeto educativo".

O espaço organizado da melhor maneira oportuniza diferentes vivências para a criança, mas todas elas terão significado se mediadas pelo educador. "O olhar de um educador atento é sensível a todos os elementos que estão postos em uma sala de aula. $\mathrm{O}$ modo como organizamos materiais, móveis, e a forma como crianças e adultos ocupam esse espaço e como interagem com ele são reveladores de uma concepção pedagógica" (HORN, 2004, p. 15).

Os educador tem o papel de analisar e perceber a importância da organização dos espaços de maneira que atenda as necessidades infantis, em preparar e organizar a sala para que permita aprendizagens e estimule o desenvolvimento da criança, promovendo as mudanças necessárias em sala de aula.

\footnotetext{
A organização da sala de aula visa, pois, viabilizar que as atividades planejadas por professores e crianças se desenvolvam de maneira flexível, criativa e cooperativa. Essa organização não é estática: novos materiais vão sendo introduzidos ou antigos são rearrumados a fim de melhor atender a esse critério (KRAMER, 1993, p.75).
}

Carvalho \& Rubiano (1995) a criatividade e o dinamismo são essenciais para construir e reconstruir diferentes ambientes em sala, o espaço retrata as diferentes vivências proporcionadas para a criança, sendo organizado pelo educador para a criança e com a criança. O auxílioda criança na modificação e construção dos espaços na creche promove a troca de 
saberes entre educadores e crianças de forma natural, além de satisfazer as necessidades e anseios das crianças.

A organização da sala deve ser planejada e realizada em parceria, entre as crianças e educadores, porém "o educador organiza o espaço de acordo com suas ideias sobre desenvolvimento infantil e de acordo com seus objetivos, mesmo sem perceber" (CARVALHO \& MENEGHINI, 20II, p.I52).

Para Carvalho \& Rubiano (1995) o adulto organiza oespaço para favorecer suas necessidades em sala, encostar móveis nas paredes e deixando grandes espaços livres ao centro, com o intuito de proteger a criança. Essas mesmas autoras destacam a importância a presença de ambientes menores, pois esses facilitam a interação entre os membros,e esta interação acontece especialmente entre criança/criança, o educador orienta e media estas interações.

Ainda de acordo com as autoras acima citadas, a organização dos espaços em sala que favorecema relação e interação entre as crianças destacam como arranjo espacial, "que diz respeito à maneira como móveis e equipamentos existentes em um local posicionam-se entre si” (CARVALHO \& RUBIANO, 1995, p. I17).

Os arranjos espaciais são compostos e delimitados por zonas circunscritas, "áreas espaciais claramente delimitadas pelo menos em três lados por barreiras formadas por mobiliário,parede, desnível do solo etc" (CARVALHO \& RUBIANO, 1995, p. I17).

\footnotetext{
Arranjo semi-aberto: é caracterizado pela presença de zonas circunscritas, proporcionando à criança uma visão fácil de todo o campo de ação, incluindo a localização do adulto e demais crianças. As crianças, geralmente em subgrupos, ocupam preferencialmente as zonas circunscritas, mesmo quando afastadas do adulto;em tais zonas geralmente ocorrem interações afiliativas entre crianças. Arranjo aberto: Há ausência de zonas circunscritas, geralmente havendo um espaço central vazio. As interações entre crianças são raras, as quais tendem a permanecer em volta do adulto, porém ocorrendo pouca interação com o mesmo. Arranjo fechado: Há a presença de barreiras físicas, por exemplo um móvel alto, dividindo o local em duas ou mais áreas, impedindo uma visão total da sala. As crianças tendem a permanecer em volta do adulto, evitando áreas onde a visão do mesmo não é possível, havendo poucas interações entre crianças (LEGENDRE, 1983, 1986, 1987 apud CARVALHO \& RUBIANO, 1995, p.ri8).
}

Dependendo do modo como o educador organiza todo o espaço em sala poderá dificultar ou favorecer a interação entre as crianças e educador. $O$ planejamento das atividadese da organização adequada do espaço permite a participação e interação das crianças durantea prática educativa. Referencial Curricular Nacional para a Educação Infantil (1998, 
p. 58):

A organização dos espaços e dos materiais se constitui em um instrumento fundamental para a prática educativa com crianças pequenas. Isso implica que, para cada trabalho realizado com as crianças, deve-se planejar a forma mais adequada de organizar o mobiliário dentro da sala, assim como introduzir materiais específicos para a montagem de ambientes novos, ligados aos projetos em curso.

Portanto, cabe ao educador planejar e refletir sobre o espaço educativo adequado, ser acolhedor, sociável e contribuir para o dia a dia da criança e agregar conhecimentos acerca da família, escola e sociedade.

\subsection{Os espaços físicos}

Os diferentes espaços que se formam dentro do contexto da educação infantil necessitam ser planejados, pois são fundamentais para o educador exercer com qualidade sua proposta educativa, o espaço é considerado ferramenta essencial para o desenvolvimento integral da criança "O espaço físico e social é fundamental para o desenvolvimento das crianças, na medida em que ajuda a estruturar as funções motoras, sensoriais, simbólicas, lúdicas e relacionais" (BARBOSA \& HORN, 200I, p. 73).

O Referencial Curricular Nacional para a Educação Infantil (1998) destaca o valor dos espaços físicos internos e externos serem organizados com o proposito de favorecerem o desenvolvimento e aprendizagem, sempre adequados a faixa etária da criança.

A importância de espaços físicos também é abordado nas Diretrizes Curriculares Nacionais da Educação Básica (2013, p. 93): “a criança deve ter possibilidade de fazer deslocamentos e movimentos amplos nos espaços internos e externos às salas de referência das turmas e à instituição, envolver-se em explorações e brincadeiras com objetos e materiais diversificados que contemplem as particularidades das diferentes idades [...]”.

Os momentos de recreação nos diferentes espaços são fundamentais para a criança, a sua organização é consistente com o comportamento que a criança irá demonstrar, e o nível de interação que irá desenvolver com o espaço e com outras pessoas.

É preciso refletir sobre o momento de desenvolvimento da criança para organizar as áreas de recreação. Crianças menores necessitam de uma delimitação mais clara do espaço, correndo o risco de se desorganizarem quando este é muito amplo e disperso[...] À medida que a criança vai crescendo, esses ambientes poderão ir se expandindo, favorecendo a exploração e o desenvolvimento físico-motor (PARÂMETROS BÁSICOS DE INFRA-ESTRUTURA PARA INSTITUIÇÕES DE EDUCAÇÃO INFANTIL, 2006, p. 27). 
Ao respeitar a idade e fase de desenvolvimento da criança o educador auxilia na formação da compreensão do espaço, onde a criança irá sentir-se segura para os deslocamentosnecessários na instituição. Uma preocupação dos educadores relaciona-se aos espaços internos ou externos para momentos de descanso e isolamento, Parâmetros Básicos de Infraestrutura para Instituições de Educação Infantil (2006, p. 28): "Oferecer também áreas mais reservadas que permitam, em certos momentos, a preservação da individualidade ou o atendimento à necessidade de concentração e isolamento; cantos isolados ou áreas suspensas podem ser criados, permitindo que as crianças tenham refúgios e locais secretos”.

Para Barbosa \& Horn (200I) os espaços educativos não podem ser um igual ao outro, pois o mundo é cheio de contraste, e a creche precisa mostrar a ela a grande diversidade existente, e a importância da criança saber lidar com isso. A criança, ao frequentar a creche, deve desenvolver-se para conhecer o mundo, onde as aprendizagens obtidas facilitem sua interação com o mundo externo.

A importância da organização de espaços externos é fundamental para a criança explorar o ambiente, vivenciar os momentos que proporcione o desenvolvimentode suas capacidades tanto físicas quanto motoras, conforme sua faixa etária.

De acordo com o Referencial Curricular Nacional para a Educação Infantil (1998) os espaços externos precisam ser lúdicos e alternativos, para que as crianças possam correr, pular,balançar, descer, escorregar. Em áreas externas todos os brinquedos disponíveis para as crianças interagirem devem estar em condições seguras, evitando sempre maiores preocupações. "Os aparelhos fixos de recreação, quando existirem, devem atender às normas de segurança do fabricante e ser objeto de conservação e manutenção periódicas” (PARÂMETROS BÁSICOS DE INFRA-ESTRUTURA PARA INSTITUIÇÕES DE EDUCAÇÃO INFANTIL, 2006, p. 28).

Os espaços das instituições de educação infantil permitem à criança diversas aprendizagens, o contato com o ambiente, natureza, remete a um lugar encantador e funcional. "A interação com o ambiente natural estimula a curiosidade e a criatividade. Sempreque for possível, deve-se prover um cuidado especial com o tratamento paisagístico, que inclui não só o aproveitamento da vegetação, mas também os diferentes tipos de recobrimento do solo, como areia, grama, terra e caminhos pavimentados" (PARÂMETROS BÁSICOS DE INFRA - ESTRUTURA PARA INSTITUIÇÕES DE EDUCAÇÃO INFANTIL, 2006, p. 26). 
Os aspectos estético-compositivos dizem respeito à imagem e à aparência, traduzindo- se em sensações diferenciadas que garantam o prazer de estar nesse ambiente. Nessa vertente estão incluídas a diversidade de cores, texturas e padrões das superfícies, o padrão construtivo, as formas, as proporções, os símbolos, os princípios compositivos,enfim, os elementos visuais da edificação, que podem ser trabalhados para despertar os sentidos, a curiosidade e a capacidade de descoberta da criança, e que, de certa forma, excitem o imaginário individual e coletivo.

Todos os espaços e ambientes das instituições de ensino de Educação Infantil merecem a devida importância, todos os detalhes são componentes para o bem-estar da criança com o meio $e$ as pessoas que dele fazem parte. Ressaltam-se alguns itens fundamentais a serem observados durante a elaboração de projetos de construção, manutenção e adaptação, para facilitar o desenvolvimento da criança de forma segura e auxiliar o educador no cuidar e educar.

Conforme os Parâmetros Básicos de Infraestrutura para Instituições de Educação Infantil (2006, p. 25): "Nos banheiros, a autonomia das crianças vai estar relacionada àadaptação dos equipamentos às suas proporções e alcance [...] os banheiros devem ser tambémde fácil acesso, com localização próxima às salas de atividades e às áreas de recreação evivência [...]”. O banheiro estruturado de modo correto possibilita à criança desenvolver a autonomia durante as atividades do dia-a-dia, sem precisar da ajuda do educador.

As áreas destinadas ao preparo e ao cozimento dos alimentos devem ser reservadas ede difícil acesso às crianças, evitando-se acidentes; pode-se solucionar a restrição ao acesso utilizando portas à meia altura, que proporcionam segurança às crianças sem restringir a ventilação [...] O refeitório deve distinguir e setorizar duas áreas distintas:preparo de alimentos e refeição. É importante que possibilite boas condições de higiene, ventilação e segurança; prever mobiliário adequado tanto à refeição das crianças quanto à dos adultos (PARÂMETROS BÁSICOS DE INFRA- ESTRUTURA PARA INSTITUIÇÕES DE EDUCAÇÃO INFANTIL, 2006, p. 30).

Os múltiplos espaços das instituições devem ser estruturados, permitindo criança se desenvolver de modo seguro e agradável, restringindo as áreas de perigo e oferecendo agradáveis momentos de aprendizagem. Os móveis acessíveis às crianças favorecem a troca de conhecimentos, auxiliando na aquisição de habilidades motoras.

Os espaços são compostos por diferentes detalhes, cada um com seu significado e relevância, o educador deve auxiliar e estimular a criança para que ela possa observar tudo que a cerca, desta forma Barbosa \& Horn(200I, p. 73): "devemos levar em consideração que o ambiente é composto por gosto, toque, sons e palavras, regras de uso do 
espaço, luzes e cores, odores, mobílias, equipamentos e ritmosde vida. Também é importante educar as crianças no sentido de observar, categorizar, escolhere propor, possibilitando-lhes interações com diversos elementos".

As creches são espaços preparados para as crianças, são ambientes que transmitem tranquilidade, alegria, e para isso é necessário que o espaço seja adequado para as experiências oferecidas às crianças .Os Parâmetros Básicos de Infraestrutura para Instituições de Educação Infantil (2006, p. 30) ressaltam o valor dos detalhes, como as cores; "as cores têm importância fundamental para os ambientes destinados à educação da primeira infância, pois reforçam o caráter lúdico, despertando os sentidos e a criatividade”.

O uso da cor, além do papel estimulante ao desenvolvimento infantil, pode ser também um instrumento eficaz de comunicação visual, identificando ambientes e setores. Horn (2004, p. 18): "a harmonia das cores, as luzes, o equilíbrio entre móveis e objetos, a própria decoração da sala de aula, tudo isso influenciará na sensibilidade estética das crianças, ao mesmo tempo em que permitirá que elas apropriem dos objetos da cultura na qual estão inseridas".

Os Parâmetros Básicos de Infraestrutura para Instituições de Educação

Infantil (2006) destacam a importância e adequação da sala de entrada/chegada ao berçário, tratamento adequado com paisagismo, proteção contra intempéries, comunicação visual, onde os berçários estão claramente orientados. A entrada principal deve ser distinta e receptiva e diferenciar o jardim de infância como unidade educacional por meio de fotos nas paredes e elementos infantis. A creche "convida" para as experiências internas, mas deve proteger e garantir a segurança das crianças.

O espaço da escola deve ser seguro e devefavorecer a ampla circulação das crianças, tanto nas salas de aula, quanto no pátio externo, na sala de refeições, banheiros etc. É fundamental que as crianças conheçam o espaço e nele se movimentem livre e organizadamente (KRAMER, 1993, p. 74).

A organização dos espaços deve ser entendida pelos profissionais da educação como essencial no contexto escolar, sendo uma ferramenta pedagógica que pode ser utilizada positivamente na prática educativa, além de favorecer a aprendizagem e o desenvolvimento da criança.

A criança sente-se segura ao conhecer todo o ambiente da creche, visto que frequenta esse espaço diariamente, e sua interação com o ambiente facilita a troca de ambientes pelas diferentes atividades realizadas no cotidiano. 


\section{CONCLUSÃO}

A organização dos espaços deve ser entendida pelos educadores como essencial no contexto escolar, visto que é um instrumento pedagógico que pode ser utilizado positivamente na prática pedagógica e promove a aprendizagem e o desenvolvimento da criança.

Cabe, ao educador planejar e refletir sobre o espaço educativo adequado, sendo acolhedor e sociável, contribuindo para o dia a dia da criança e combinando conhecimentos sobre a família, a escola e a sociedade.

A sala deve ser desafiadora, estimulante, acolhedora, despertar interesse, despertar participação, oferecer jogos, criar jogos, imaginar, construir; "Viagem" ao mundo das fantasias, sentido que possibilita uma produção lúdica de conhecimento para que a criança supere seus limites e desenvolva suas potencialidades, desenvolvendo diferentes áreas do conhecimento cognitivo e motor.

\section{REFERÊNCIAS BIBLIOGRÁFICAS}

BARBOSA, Maria Carmen Silveira; HORN, Maria da Graça. Organização do Espaço e do Tempo na Escola Infantil. In: CRAIDY, Carmem; KAERCHER, Gládis. Educação Infantil:Pra que te quero? Porto Alegre, RS: Artmed, 20or.

BRASIL. Lei de Diretrizes e Bases da Educação Nacional: Lei nº.394 de 20-I2-1996. Disponível em http://www.planalto.gov.br. Acesso em 03/II/202I.

BRASIL. Referencial Curricular Nacional para a Educação Infantil. Brasília: MEC, 1998.

BRASIL. Diretrizes Curriculares Nacionais da Educação Básica. Brasília: MEC, 2013.

BRASIL. Manual Técnico de Arquitetura e Engenharia. Brasília: MEC/FNDE, 2009. Disponível

file:///D:/Usuario/Downloads/cartilha_proinfancia_projetos_proprios.pdf. Acesso em 03/II/2021.

BRASIL. Parâmetros básicos de infraestrutura para instituições de educação infantil. Brasília: MEC, 2006. Disponível em http://portal.mec.gov.br. Acesso em 03/II/202I.

CARVAlHO, Mara I. Campos; RUBIANO, Marcia R. Bonagamba. Organização do 
espaçoem Instituições Pré-Escolares. In: OLIVEIRA, Zilma de Moraes Ramos (Org.). Educação Infantil: muitos olhares. 2. ed. São Paulo: Cortez, 1995.

CARVALHO, Mara Campos; MENEGHINI, Renata. Estruturando a sala. In: ROSSETTI-FERREIRA, Maria Clotilde (Org.). Os Fazeres na Educação Infantil. ı2. ed. São Paulo:Cortez, 2oiı.

HORN, Maria da Graça Souza. Sabores, cores, sons, aromas: A organização dos espaços naEducação Infantil. Porto Alegre, RS: Artmed, 2004.

KRAMER, Sonia (Org.). Com a Pré-Escola nas mãos: Um alternativa curricular para aEducação Infantil. São Paulo: Ática, 1993.

NISTA-PICCOLO, Vilma Lení; MOREIRA, Wagner Wey. Corpo em Movimento naEducação Infantil. São Paulo: Cortez, 2012. 